\title{
Community services in multiple sclerosis: still a matter of chance
}

\author{
J A Freeman, A J Thompson
}

\begin{abstract}
Objectives-People with multiple sclerosis often have multiple complex needs that require input from a wide range of services. Many complain that services are inadequate and poorly coordinated. Few studies have been undertaken to support this contention and objective data are scarce. The level of services and home modifications received by people with multiple sclerosis across a broad range of disease severity has been investigated. Methods-As part of a quality of life study, 150 adults with clinically definite multiple sclerosis were interviewed, using a structured questionnaire, to determine their current use of outpatient and community services and the home modifications in place. Disability, handicap, and emotional status were also measured.
\end{abstract}

Results-Forty five per cent of people did not receive any community services other than contact with their general practitioner. Thirty nine per cent of people with moderate and $12 \%$ with severe disability failed to receive community services. For the services received: $17 \%$ had contact with a community nurse; $33 \%$ with a care attendant or home help; $23 \%$ with a physiotherapist, $21 \%$ with an occupational therapist, and $10 \%$ with a social worker. Fifty eight per cent of people had modifications to their home as a direct result of multiple sclerosis. The relation between level of disability and number of services and adaptations received was moderate $(r=0.58$ and 0.54 respectively $)$ and the relation between level of services and age $(r=0.12)$, living alone $(r=0.16)$, and emotional status $(r=0.10)$ was negligible.

Conclusions-Despite a shift of emphasis from hospital to community care, and the establishment of standards of care for multiple sclerosis, many people with moderate or severe disability fail to receive assistance. These results provide evidence to support the dissatisfaction felt by people with multiple sclerosis in relation to the services they receive. It raises questions about equitable allocation of resources and highlights the urgent need for a review of community services.

(F Neurol Neurosurg Psychiatry 2000;69:728-732)

Keywords: community services; multiple sclerosis; service delivery

Professor A J Thompson

a.thompson@ion.ucl.ac.uk

Received 14 September 1999 and in final form

13 April 2000

Accepted 20 April 2000

A comprehensive model of care for patients with chronic progressive conditions such as multiple sclerosis involves many agencies and departments, crossing hospital, community, and social services. It is widely agreed, by both patients and health professionals, that continuity and coordination of care between these services is essential to best meet the needs of the patient. ${ }^{1}$ The term "seamless service" has been used in this context. Reports from people with multiple sclerosis and their carers suggest that, in reality, such a service does not exist. ${ }^{23}$ Many report that continuity and coordination of care is seriously deficient in most parts of the country; services are fragmented, communication is poor, goals are often not shared, and there is an unacceptable delay in the onset of these services once they have been recommended. ${ }^{4}$

Unfortunately most evidence in this area is anecdotal and few studies have systematically and objectively investigated these issues. One study, undertaken over 10 years ago by McLellan et $a l,{ }^{2}$ investigated the way in which multiple sclerosis affects the personal lives of people with the disease in the district of Southampton, United Kingdom. In depth interviews with 305 people with multiple sclerosis and their relatives, were undertaken to examine a wide range of issues, including quantification of the level of community services received. The survey showed that services were often inadequate, failing to meet the needs of people with multiple sclerosis and their carers. They concluded that prospective studies, in which populations are regularly sampled at intervals over a period of years, are necessary to evaluate the evolution of disability and to monitor changes in the delivery of services. Despite the ever increasing emphasis on care in the community, ${ }^{5}$ little work has been undertaken since then. No studies have examined how the supply of community services at home compares with demand. This type of information on the utilisation of medical and social services is essential for good healthcare planning. ${ }^{6}$

Recently we have undertaken research investigating the quality of life in people with multiple sclerosis. ${ }^{7}$ Integral to this study was a structured interview that recorded the persons' accounts of their current use of community and hospital outpatient services, as well as any home modifications that were put in place as a direct result of their multiple sclerosis. We decided to retrospectively analyse the untapped body of information gathered from these interviews in an attempt to increase our understanding of this area.

\section{Methods}

The cohort comprised 150 patients with clinically definite multiple sclerosis, representing a 


\begin{tabular}{|c|c|c|c|c|}
\hline & $\begin{array}{l}\text { Total sample } \\
n=150\end{array}$ & $\begin{array}{l}\text { Mild } \\
\text { EDSS } 0-4.5 \\
n=48\end{array}$ & $\begin{array}{l}\text { Moderate } \\
\text { EDSS 5.0-6.5 } \\
n=51\end{array}$ & $\begin{array}{l}\text { Severe } \\
\text { EDSS } 7.0-9.5 \\
n=51\end{array}$ \\
\hline Women (\%): & 68 & 60 & 67 & 76 \\
\hline Age (y) (mean (SD) (range)) & $44.6(10.8)(24-78)$ & $41.4(10.2)(24-68)$ & $45.4(10.7)(24-78)$ & $47.1(10.6)(24-73)$ \\
\hline \multicolumn{5}{|l|}{ Disease pattern (\%): } \\
\hline Secondary progressive & 50 & 2 & 71 & 76 \\
\hline Primary progressive & 11 & 13 & 8 & 12 \\
\hline Relapsing remitting & 33 & 66 & 21 & 12 \\
\hline Benign & 6 & 19 & 0 & 0 \\
\hline Years since first symptoms (mean (SD) (range)) & $14.6(8.9)(0.6-43)$ & $12.3(9.3)(2-41)$ & $15.7(8.3)(0.6-40)$ & $16.0(8.5)(1.4-43)$ \\
\hline Years since diagnosis (mean (SD) (range)) & $10.2(7.6)(0.1-38)$ & $7.5(7.8)(0.1-30)$ & $10.8(7.2)(0.2-38)$ & $12.1(7.2)(1.2-33)$ \\
\hline \multicolumn{5}{|l|}{ Marital status (\%): } \\
\hline Married/cohabiting & 70 & 83 & 63 & 67 \\
\hline Separated/divorced & 11 & 4 & 12 & 17 \\
\hline Widowed & 2 & 0 & 4 & 2 \\
\hline Single, never married & 17 & 13 & 21 & 14 \\
\hline \multicolumn{5}{|l|}{ Employment status (\%): } \\
\hline Employed & 33 & 60 & 25 & 15 \\
\hline Student or homemaker & 14 & 15 & 12 & 16 \\
\hline Retired, age & 3 & 4 & 4 & 2 \\
\hline Retired, medical & 46 & 13 & 57 & 65 \\
\hline Unemployed & 4 & 8 & 2 & 2 \\
\hline \multicolumn{5}{|l|}{ Accommodation (\%): } \\
\hline Owner occupied & 75 & 77 & 78 & 70 \\
\hline Rented (local authority) & 12 & 6 & 6 & 22 \\
\hline Rented (privately) & 6 & 6 & 10 & 2 \\
\hline Other (eg, residential unit) & 7 & 11 & 6 & 6 \\
\hline \multicolumn{5}{|l|}{ Household: lives: } \\
\hline Alone (\%) & 17 & 8 & 23 & 18 \\
\hline with spouse, family, or friend (\%) & 79 & 88 & 73 & 80 \\
\hline other $(\%)$ & 4 & 4 & 4 & 2 \\
\hline
\end{tabular}

collected as part of a cross sectional quality of life study; the design of which has been reported in detail elsewhere. ${ }^{7}$ In brief, consecutive patients were recruited from three different sources within an urban healthcare setting: a weekly outpatient assessment clinic, an inpatient neurorehabilitation unit, and those admitted under one consultant (AJT) to acute hospital wards. All patients completed a range of questionnaires and a structured interview examining: sociodemographic (sex, age, occupation, marital, and residential status, and main carer) and diagnostic status (type of multiple sclerosis, time since onset of first symptoms, and time since confirmation of diagnosis); level of disability, as assessed by a neurological registrar, using the expanded disability scale $\left(\mathrm{EDSS}^{8}\right.$ ) level of handicap (London handicap scale, $\mathrm{LHS}^{9}$ ); emotional status (general health questionnaire, $\mathrm{GHQ}^{10}$ ); and quality of life $\left(\mathrm{SF}-36^{11}\right)$ and current use of outpatient and community services and the environmental (home) modifications in place.

Only those services or modifications provided as a direct result of multiple sclerosis were reported.

ANALYSIS

The post hoc analysis was question driven. The questions were:

Table 2 Number of services received

\begin{tabular}{lllll}
\hline $\begin{array}{l}\text { Number of services } \\
\text { received }\end{array}$ & $\begin{array}{c}\text { Total sample } \\
(n=150) n(\%)\end{array}$ & $\begin{array}{c}\text { Mild }(n=48) \\
n(\%)\end{array}$ & $\begin{array}{l}\text { Moderate }(n=51) \\
n(\%)\end{array}$ & $\begin{array}{l}\text { Severe }(n=51) \\
n(\%)\end{array}$ \\
\hline No service at all & $67(45)$ & $41(86)$ & $20(39)$ & $6(12)$ \\
Private help only & $8(5)$ & $2(4)$ & $4(8)$ & $2(4)$ \\
Reviewed only & $17(11)$ & $2(4)$ & $8(15)$ & $6(12)$ \\
One & $20(13)$ & $1(2)$ & $10(22)$ & $9(17)$ \\
Two & $13(9)$ & $1(2)$ & $6(10)$ & $7(14)$ \\
Three & $11(7)$ & $0(0)$ & $3(6)$ & $8(15)$ \\
Four & $7(5)$ & $1(2)$ & $0(0)$ & $6(12)$ \\
Five & $7(5)$ & $0(0)$ & $0(0)$ & $7(14)$ \\
\hline
\end{tabular}

All percentages are rounded.
-What are the range and intensity of services/home modifications received by these patients?

-Are the number of services or modifications related to the level of disability, handicap, or emotional status; or to sociodemographic characteristics such as age or living alone?

All data were analysed using SPSS Version 7.5. ${ }^{12}$ Descriptive statistics were used to define the sample's demographic and diagnostic characteristics, and the frequency of services and home modifications provided.

The sample was subdivided into two categories: those receiving services and those who were not (a help-no help dichotomy). The two groups were compared against a series of measures using $t$ tests.

Pearson correlation coefficients were used to examine the relation between the number of services or modifications received and a range of diagnostic and sociodemographic characteristics.

\section{Results}

PATIENTS AND THE SERVICES RECEIVED

Table 1 provides the demographic and diagnostic characteristics of the total sample, as well as a breakdown of these characteristics according to different levels of disease severity.

Table 2 details the percentage of people currently receiving a range of services, including district nursing, care attendants, home help, occupational therapy (either community or outpatient), physiotherapy (either community, outpatient, or private), social work, and attendance at a day centre. Forty five per cent of people did not receive any form of community services whatsoever, with a further $5 \%$ only receiving assistance in the form of self financed private home help.

The range of EDSS scores was examined according to the frequency of services received. 
Table 3 Details of services currently being received

\begin{tabular}{llllll}
\hline Service & $\begin{array}{l}\text { Total sample } \\
(n=150)\end{array}$ & $\begin{array}{l}\text { EDSS Range } \\
(\text { mean }(S D))\end{array}$ & $\begin{array}{l}\text { Mild } \\
(n=48) n(\%)\end{array}$ & $\begin{array}{l}\text { Moderate } \\
(n=51) n(\%)\end{array}$ & $\begin{array}{c}\text { Severe } \\
(n=51) n(\%)\end{array}$ \\
\hline Community nursing & $25(17)$ & $3.5-9.0(7.7(1.2))$ & $1(2)$ & $5(10)$ & $19(37)$ \\
Care attendant & $19(13)$ & $6.5-8.5(8.0(0.8))$ & $0(0)$ & $1(2)$ & $18(35)$ \\
Home help & $30(20)$ & $3.5-8.5(7.1(1.1))$ & $1(2)$ & $11(22)$ & $18(35)$ \\
Physiotherapy & $35(23)$ & $3.5-9.0(7.0(1.3))$ & $4(8)$ & $12(24)$ & $19(37)$ \\
Occupational therapy & $31(21)$ & $3.5-9.0(7.2(1.0))$ & $1(2)$ & $9(18)$ & $21(41)$ \\
Social work & $15(10)$ & $3.5-9.0(7.1(1.7))$ & $2(4)$ & $3(6)$ & $10(20)$ \\
Day centre & $6(4)$ & $7.0-8.5(8.1(0.6))$ & $0(0)$ & $0(0)$ & $6(12)$ \\
\hline
\end{tabular}

This disclosed that the range of disability in people who received services was large (EDSS range 3.5-9.0, mean 7.0 (SD1.2)). Of the people receiving services $(\mathrm{n}=83) ; 9 \%$ were mildly $(n=7), 37 \%(n=31)$ were moderately, and $54 \%$ $(n=45)$ were severely disabled. Although on average, people who did not receive any services were less disabled (mean EDSS 4.2 (SD 1.9)), their range of EDSS scores was also large (EDSS 1.0-9.0). It is notable that 39\% $(n=20 / 51)$ of moderately and $12 \%(n=6 / 51)$ of severely disabled people failed to receive any community services.

To determine whether this difference was significant, the sample was subdivided into two groups according to a help-no help dichotomy, and then compared against a series of measures using $t$ tests. The results indicated that significant differences $(p<0.05)$ existed between the two groups for the number of years since diagnosis $(p<0.02)$; the level of disability $(p<0.001)$ and handicap $(\mathrm{p}<0.0001)$; and whether or not the person was living alone $(\mathrm{p}<0.04)$. Differences between the groups were not significant for age, emotional status, or number of years since first symptoms.

SPECIFIC SERVICES RECEIVED

Table 3 provides a breakdown of the specific services received.

Community nurses were in contact with 25 people $(17 \%)$ within this total sample; in 13 cases this was only for review. Of the 25 people, five were moderately disabled and 19 were severely disabled. This meant that only $24 \%$ of those people who were either moderately or severely disabled had district nursing contact. Of those seeing a nurse, five $(20 \%)$ had daily contact; two $(8 \%)$ were seen two to three times a week, five $(20 \%)$ on a weekly basis, and 13 $(52 \%)$ were seen less often than weekly. It is interesting that there was little difference in terms of disease severity between those receiving nursing contact five or more times a week (EDSS range 6.5-9.0, mean 8.1) and those receiving it between one to three times a week (EDSS range 7.5-8.5, mean 8.3).

Table 4 Number of home adaptations in situ

\begin{tabular}{|c|c|c|c|c|}
\hline Number of adaptations & $\begin{array}{l}\text { Total sample } \\
(n=150) n(\%)\end{array}$ & $\begin{array}{l}\text { Mild } \\
(n=48) n(\%)\end{array}$ & $\begin{array}{l}\text { Moderate } \\
(n=51) n(\%)\end{array}$ & $\begin{array}{l}\text { Severe } \\
(n=51) n(\%)\end{array}$ \\
\hline No of adaptations & $63(42)$ & $41(85)$ & $16(31)$ & $6(12)$ \\
\hline Purpose built house & $17(11)$ & $0(0)$ & $4(8)$ & $13(25)$ \\
\hline One & $23(15)$ & $5(11)$ & $12(23)$ & $6(12)$ \\
\hline Two-three & $33(22)$ & $1(2)$ & $15(30)$ & $17(33)$ \\
\hline Four-six & $12(8)$ & $1(2)$ & $4(8)$ & $7(14)$ \\
\hline Seven or more & $2(2)$ & $0(0)$ & $0(0)$ & $2(4)$ \\
\hline
\end{tabular}

Possible alterations=extension, stair lift, rails, ramps, widening of doors, intercom system, level access shower, kitchen alterations, bathroom alterations, overhead hoist tracking system, level access.
Thirty three per cent of people had assistance from either a home help or a carer attendant; with seven people receiving both of these services. Those receiving the greatest amount of help in this area tended to be the more severely disabled (EDSS range 6.0-9.0, mean 8.2 ). When help was provided to severely disabled people it was often on an intensive basis with $28(54 \%)$ of this group receiving help at least once a day. Of note, the EDSS range was large for people who did not receive any assistance from either home help or carer attendants (EDSS 1.0-9.0).

A total of 35 people (23\%) accessed physiotherapy services either within the community $(n=13)$ or on a hospital outpatient basis $(n=22)$. In addition a further five self funded private physiotherapy. Of these, 17 people were seen on a review basis only. There was a notable distinction in the level of disease severity between those attending outpatient therapy (EDSS range 3.58.5, mean 6.5 (SD 1.4)) and those receiving therapy in the community (EDSS range 6.59.0, mean 7.5 (SD 0.8)). People seen in the community tended to be essentially wheelchair bound; $77 \%$ of these people scored an EDSS of 7.0 or more, by contrast with only $38 \%$ of the outpatient attendees.

Thirty one people (21\%) were in contact with an occupational therapist in the community. Of these, only one person was being seen on a regular basis with all others reporting that they contacted the therapist directly when the need arose. Fifteen people (10\%) were in contact with a social worker; in the vast majority of cases $(n=13)$ this was only on a review basis. Six people (4\%) attended a day centre, all of whom were severely disabled (EDSS range 7.0-8.5, mean 8.1 (SD 0.5)).

ENVIRONMENTAL (HOME) MODIFICATIONS

Table 4 details the number of home modifications that were in place as a direct result of multiple sclerosis. In total 87 people $(58 \%)$ had modifications to their home. The range of severity of disability in people who had home modifications was large (EDSS range 2.5-9.0), although a smaller proportion were mildly disabled $(8 \%, \mathrm{n}=7 / 87)$ compared with moderately $(40 \%, \mathrm{n}=35 / 87)$ or severely disabled $(52 \%, \mathrm{n}=45 / 87)$.

Of the total sample, 17 people (11\%) lived in a purpose built house and a further $14(9 \%)$ had major alterations such as a purpose built extension, or their living room altered to become their bedroom. All those living in a purpose built house were moderately or severely disabled (EDSS range 6.5-9.0, mean 7.7 (SD 0.8)) with the majority being severely disabled. 
Of the 70 people who had home modifications (and were not living in a purpose built house), 23 had one, 33 had two or three, and 14 had four or more alterations; the overall average being 2.5 (range 1-9) alterations per person. Mildly disabled people had fewer modifications (mean 1.5 , range $1-3$ ) than those who were moderately (mean 2, range 1-4) or severely disabled (mean 3, range 1-9).

The range of modifications included wheelchair accessible kitchen $(n=3)$, wheelchair accessible bathroom $(n=15)$, level access shower $(n=26)$, rails $(n=50)$, ramps $(n=26)$, stair lift or through floor lift $(n=17)$, levelling of floor or alteration of step heights $(n=9)$, widening of doors $(\mathrm{n}=8)$, overhead tracking hoist system $(n=3)$, and intercom system $(n=4)$.

Of the total sample, 63 people $(42 \%)$ did not have any modifications to their home. Importantly, the range of disability within this group was large with EDSS scores ranging from 1.0 to 8.0 (mean 4.1 (SD 1.8)). Of these, 41 people were mildly disabled, 16 were moderately disabled, and six were severely disabled.

The percentage of people receiving home modifications was similar to the percentage receiving services. On closer examination the data show considerable overlap; $76 \%$ of people with no home modifications also had no services.

ASSOCIATION BETWEEN DEMOGRAPHIC AND DIAGNOSTIC CHARACTERISTICS WITH LEVEL OF COMMUNITY INPUT

Pearson's correlation coefficients showed that the relation between age and level of services and number of home modifications was negligible ( $r=0.12, r=0.14$ respectively). Virtually no relation was found between the number of services or home modifications and whether the person was living alone $(r=-0.16$ and $r=0.15$ respectively).

ASSOCIATION BETWEEN DISABILITY, HANDICAP, AND EMOTIONAL STATUS WITH LEVEL OF COMMUNITY INPUT

Pearson's correlation coefficients showed a moderate association between levels of disability and handicap and the number of services received ( $r=0.58$ and $r=-0.41$ respectively); and the number of home modifications in place $(r=0.54$ and $r=-0.38$ respectively). By contrast, only a weak relation was shown between the number of services or home modifications and the reported level of emotional distress ( $r=0.10$ and $r=0.13$ respectively).

\section{Discussion}

This article describes and quantifies the services and home modifications used by a cohort of 150 patients with multiple sclerosis. These patients represent a broad range of disease severity and disability; their demographic and diagnostic characteristics are typical of multiple sclerosis. ${ }^{213}$ This retrospective analysis was applied to data collected as part of a study examining quality of life issues in multiple sclerosis. Although this study was not specifically designed to answer the questions posed, the results provide a general indication of the extent of services and modifications used by people with multiple sclerosis.

The British Society of Rehabilitation Medicine has expressed the view that the medical and therapeutic measures capable of promoting health and independence, relieving discomfort, and preventing medical complications of multiple sclerosis are not put into practice as often or as effectively as they should be. ${ }^{14}$ Our results provide objective evidence to support this view. Forty five per cent of people in this sample did not receive any community services, apart from their general practitioner. Of note, $39 \%$ of people with moderate disability and $12 \%$ with severe disability did not receive any community services, suggesting that service provision was inadequate for these people. It is acknowledged that variations of service provision occur across different geographical localities and different trusts ${ }^{15}$; these results may therefore be peculiar to our sample. This is unlikely, however, as they are similar to the findings of other reports investigating service provision for a range of neurological conditions, ${ }^{16}{ }^{17}$ and more specifically, for multiple sclerosis. ${ }^{218}$ Each of these studies concluded that community services do not seem to be systematically planned or allocated, and that substantial unmet need exists. Of note, a survey of health authorities by the Association for Quality in Health Care ${ }^{18}$ found that nearly half of those who responded had no contracts at all for multiple sclerosis services. The money spent on these services varied widely between health authorities and there was no evident relation to the size or the demography of the area.

In comparing our results with those from the Southampton study undertaken over 10 years ago, ${ }^{2}$ there are remarkable similarities in the percentage of patients receiving services. This further indicates that our results are not unique to our setting. It suggests that little may have changed in the past decade in the provision of community care. In both studies many severely disabled people were not in contact with a therapist or nurse. For example, only about one third of severely disabled people (37\% in this study, $33 \%$ in the Southampton study) were receiving physiotherapy. Occupational therapy input seemed even more sporadic. Although $41 \%$ of severely disabled people in this study had contact with an occupational therapist (16\% in the Southampton study), this was on a regular basis in only one person. Finally, despite the prevalence of intellectual and emotional impairment in multiple sclerosis, only $10 \%$ of people had contact with a social worker.

The recent government initiatives set out an agenda for ensuring that the NHS delivers more responsive and informed services. ${ }^{5}$ The emphasis is on reducing inequalities in health care access and provision. This requires information about levels of service provision, and whether services are delivered on the basis of need. Currently, little information of this kind is available. This study provides preliminary information of this nature.

Defining the need for services is complex, particularly in multiple sclerosis where a 
continuous and flexible management strategy is required to meet the particular patient's needs. ${ }^{14}$ It is not possible to determine unmet need from our study method. However, conventional wisdom is that the greater the disability the more likely the need for community services. Furthermore, clinical consensus is that, at a minimum, regular review is essential in progressive deteriorating conditions, such as multiple sclerosis, to prevent unnecessary secondary complications. ${ }^{14}$ In line with other studies our results show that a moderate relation exists between the severity of disability and handicap and the number of community services received. ${ }^{19}{ }^{20}$ Importantly, however, our results also show that a significant number of moderately to severely disabled people fail to receive any services whatsoever. In many cases it is common for the burden of care to fall on the family and unpaid carers. ${ }^{20}$

These results raise questions about equitable allocation of resources. There is an urgent need to identify why this might be the case. We must question, for example, whether people fail to receive services because of limited resources, inadequate referral, or both. If resources are available but are not utilised, we must investigate whether this is because staff are ignorant about the way in which services may meet the needs of people with multiple sclerosis. These problems are not peculiar to multiple sclerosis. ${ }^{21}$ For example, despite substantial evidence demonstrating the benefit of organised multidisciplinary stroke care, ${ }^{22}$ a recent national survey showed that stroke care provision remains largely a matter of chance, with only half of United Kingdom patients receiving specialist care. ${ }^{23}$ Similarly, a recent national audit of district nursing services demonstrated large variations in referral rates between similar populations. ${ }^{15}$ It is perhaps not surprising that this is also the case for multiple sclerosis services. ${ }^{18}$ Preventing inconsistencies in community care is crucial, and particularly relevant in a climate where there is an increasing shift towards earlier hospital discharge and more comprehensive care within the community.

These results highlight the need for a structured and coordinated multiagency approach to multiple sclerosis care. They endorse the importance of national standards of care ${ }^{3}$ and guidelines of clinical practice ${ }^{24}$ for use as a benchmark for evaluation. They reinforce the need for a key worker (or coordinator) to facilitate the integration and coordination of services. ${ }^{25}$ Perhaps most importantly, they provide empirical evidence to support the dissatisfaction, reported by people with multiple sclerosis, with the community services they receive. ${ }^{4}$

\section{Conclusions}

The past 10 years have seen a marked shift of focus and resources from hospital to community care. Promises that "patients will get fair access to consistently high quality, prompt and accessible services right across the country" have been high on the political agenda. ${ }^{26}$ In parallel with this much emphasis has been placed on the establishment of national guidelines and standards of care. Despite this it seems that in practi- cal terms little has changed over the past decade. Wide and unacceptable variations in the provision of outpatient and community services remain a fundamental problem for people with multiple sclerosis. This is unacceptable and requires urgent action.

More recently the Government has sought to further address inequalities in the delivery of care through the establishment of Primary Care Groups, and strategies such as clinical governance, the creation of the National Institute for Clinical Excellence, and the Commission for Health Improvement. It remains too early to know what impact these initiatives will have. Will the next decade see positive changes in the access and coordination of community services for people with multiple sclerosis? Or, will it still remain just a matter of chance?

1 Thompson AJ, Johnston SR, Harrison J, et al. Service delivery in multiple sclerosis: the need for co-ordinated community care MS Management 1997:4:11-18.

2 McLellan DL, Martin JR, Roberts MHW, et al. Multiple sclerosis in the Southampton district. Southampton: University of Southampton Research Unit and Department of Sociology, 1989. (ISNB 0854322318X).

3 Hatch J, Johnson J, Thompson AJ. Standards of healthcare for people with multiple sclerosis. Improving healthcare in the UK. MS Management 1998;5:16-23.

4 Robinson I, Hunter M, Neilson S. $A$ dispatch from the frontline: the views of people with multiple sclerosis about their needs. A qualitative approach. London: Brunel Research Unit, June 1996.

5 NHS Executive. The new NHS modern and dependable; developing primary care groups. London: Department of Health, 1998 (HSC 1998/139).

6 Stolp-Smith KA, Atkinson EJ, Campion ME, et al. Health care utilisation in multiple sclerosis. A population based study in Olmsted County, MN. Neurology 1998;50:1594600 .

7 Freeman JA, Langdon DW, Hobart JC, et al. Clinical appropriateness: a key factor in outcome measure selection: the 36 item short form health survey in multiple sclerosis. F Neurol Neurosurg Psychiatry 2000;68:150-6.

8 Kurtzke JF. Rating neurologic impairment in multiple sclerosis: an expanded disability status scale (EDSS). Neurology 1983;33:1444-52.

9 Harwood RH, Ebrahim S. Manual of the London handicap scale. Nottingham: University of Nottingham: Department of Health Care of the Elderly, 1995.

10 Goldberg D, Williams P. A users guide to the general health questionnaire. Windsor, UK: NFER-Nelson, 1988.

11 Ware JE, Snow KK, Kosinski M, et al. SF-36 Health survey: manual and interpretation guide. Boston, Massachusetts:The manual and interpretation guide. Boston, Massachusetts:

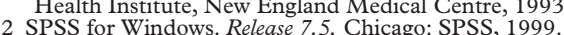

13 Weinshenker BG. Natural history of multiple sclerosis. Ann Neurol 1994;369(suppl):S6-11.

14 Compston DAS, Evans CD, Fenely RCL, et al. Working Party Report of the British Society of Rehabilitation Medicine. London: The Stationery Office, 1993

15 Audit Commission. First assessment: a review of district nursing services in England and Wales. London: Audit Commission Publications, 1999.

16 Williams $\mathrm{MH}$, Bowie C. Evidence of unmet need in the care of severely physically disabled adults. BMF 1993;306:95-8.

17 Phillips VL. Community care for severely disabled people on low incomes. BMF 1995;311:1121-3.

18 Association for Quality in Healthcare. Report of a survey of ultiple sclerosis service provision in England 1998-99. Berkshire, England: Association for Quality in Healthcare, 1998.

19 Bourdette DN, Prochazka AV, Mitchell W, et al. Health care costs of veterans with multiple sclerosis: implications for the rehabilitation of MS. Arch Phys Med Rehabil 1993;74: $26-31$.

20 Carton H, Loos R, Pacolet J, et al. Utilisation and cost of professional care and assistance according to disability of patients with multiple sclerosis in Flanders (Belgium). $f$ Neurol Neurosurg Psychiatry 1998;64:444-50.

21 Rawlins M. In pursuit of quality: the National Institute for Clinical Excellence. Lancet 1999;353:1079-82.

22 Stroke Unit Trialists Collaboration. Collaborative systematic review of the randomised trials of organised inpatient (stroke unit) care after stroke. BMF 1997;314:1151-9.

23 Ebrahim S, Redfern J. Stroke care: A matter of chance. London: The Stroke Association, 1999.

24 Miller DM, Uccelli MM, Shindell S. Multiple sclerosis clinical practice guidelines. MS Management 1998;5:1-13.

25 Johnson J. What can specialist nurses offer in caring for people with multiple sclerosis? In: Thompson AJ, Polman CO, ple with muld R, eds. MS: clinical challenges and controversies. London: Martin Dunitz, 1997.

26 Department of Health. The new NHS modern and dependable. London: Department of Health, 1997. (Cm 3807.) 